\title{
Anthropogenic air pollution sources
}

\author{
Francisc Popescu and Ioana Ionel \\ University "Politehnica" from Timisoara \\ Romania
}

\section{Introduction}

What one experiences today as atmosphere is a transient snapshot and result of its evolutionary history. Much of the development and present status was explained based both on scientific knowledge, and combined with established facts, even speculation. The planet Earth was formed around 4600 million years ago by the gravitational accretion of relatively small rocks and dust, within the solar nebula. The first evidence of single-celled life, for which tiny oxygen concentration was an essential prerequisite, is shown in the fossil record from around 3000 million years ago. Subsequently, the process of respiration led to a gradual increase in the atmospheric oxygen concentration. This in turn allowed the development of $\mathrm{O}_{3}$ which is thought to have been a necessary shield against solar $\mathrm{UV}$. Subsequent evolution of the atmosphere has been dominated by the balance between production and consumption of both $\mathrm{CO}_{2}$ and $\mathrm{O}_{2}$ (Colls, 2002).

Presently the lower part of the atmosphere is known as *air* and is formed by mainly nitrogen, oxygen and other gases, trace gases and particles. The composition, even if is suspected to major changes, is under the influence of the man kind evolution, both in terms of population number growth, as in industrial and agricultural and household development (in one word civilization). The energy consumption and technical evolution related to these sources is one main cause of the man made pollution, causing modification of the air quality, above limits, stipulated generously in legislation, adapted and modified according the to the level of knowledge, permanently. These anthropogenic pollution sources are exhausting diverse specific species to the free atmosphere and are stressing over the limit the natural possibility of the ecosystem to adapt or to cover these caused concentration augmentation. One has to notice that all the man made sources (from industry, agriculture, transportation, household sources, etc.) are contributing to the air quality level in addition to the natural sources, that existed since the Earth was created and in direct dependence to it.

The population reached presently over 6 billion, is now forecast to reach 7.5 billion by 2020 and will be stabilize at approx. 9 billion by $2050.90 \%$ of the future growth will occur in developing countries, and most of that will be concentrated in urban areas.

By their nature, the air pollution sources can be classified, mainly, as physical, chemical and biological sources, secondly as natural and anthropogenic sources, further on climate change relevant or not. The physical pollution of the atmosphere is a consequence energy input like sound and heat energy. The most relevant physical pollution sources are the direct thermal pollution, natural or anthropogenic. The local climate is changed by heat 
(caloric input) generated by industry, household, agricultural and transportation and the air from the lower atmosphere will have an increased local temperature. The indirect thermal pollution is a consequence of greenhouse effect and takes place in the troposphere and is linked to chemical anthropogenic pollution and its evolution in reference to the greenhouse gases.

The chemical pollution of the atmosphere is a consequence of the chemical compounds input, over the natural air constituents and is of natural and artificial origin. However, the natural chemical pollution sources like volcanoes eruption, natural decomposition of organic substances or fire (naturally occurred) are not of major concern as they are part of natural environment equilibrium. However, the anthropogenic chemical pollution is of major concern as their sources are increasing in number and concentration with the increase of global human population and our continuously increase of energy demand.

The anthropogenic chemical pollution has no borders and no matter where the pollutants are released into the atmosphere will have an impact over global environment. The most relevant sources are the incineration of fossil fuels to produce energy (heat and electricity), major industrial processes (like metallurgy industry or cement/construction industry) and transportation. We will classify the anthropogenic chemical pollution sources into two major groups: stationary and mobile sources.

In the chapter one will bring to attention main stationary and mobile sources of anthropogenic chemical pollution, on their causes and formation and not at least on measures to reduce their emissions. The main possibilities to reduce pollution level by correct and active measures, from which most are related to economy and balanced efficient energy use, are also presented.

The four major groups of gaseous air pollutants by historical importance, concentration, and overall effects on plants and animals (including people), are sulphur dioxide $\left(\mathrm{SO}_{2}\right)$, oxides of nitrogen (NOx: $\left.\mathrm{NO}, \mathrm{NO}_{2}\right)$, carbon dioxide $\left(\mathrm{CO}_{2}\right)$ and ozone $\left(\mathrm{O}_{3}\right)$. Sulphur dioxide and nitric oxide (NO) are primary pollutants - they are emitted directly from sources. We shall start by looking at the main sources of these and other primary gases, and also consider some of the methods of control that can be used to reduce emissions and concentrations when required.

The most important groups of anthropogenic air pollution sources are defined by industrial processed, residential heating systems, transportation (terrestrial, naval and aerial) and agricultural systems.

The majority of the pollutants are the direct result of the combustion process in large power plants and piston engines so that the first steps to reduce the pollutants concentration from atmosphere is to control and reduce the emissions from those source groups.

In this chapter we will deal mainly with the pollutants generated from combustion processes in large boilers and piston engines, as a result of the combustion process of fossil fuels.

In the ideal case the combustion process is complete (perfect) and the exhaust gazes are formed only from $\mathrm{CO}_{2}$ and $\mathrm{H}_{2} \mathrm{O}$. To achieve the complete combustion is necessary to obtain a combustion air-fuel ratio (different for each type of combustion chamber) constant into the whole combustion chamber and this is not possible due to limitations is the construction of the combustion chamber. In figure 1 a short and simplified relation between fuel, combustion, combustion products (pollutants) and air quality is given. 


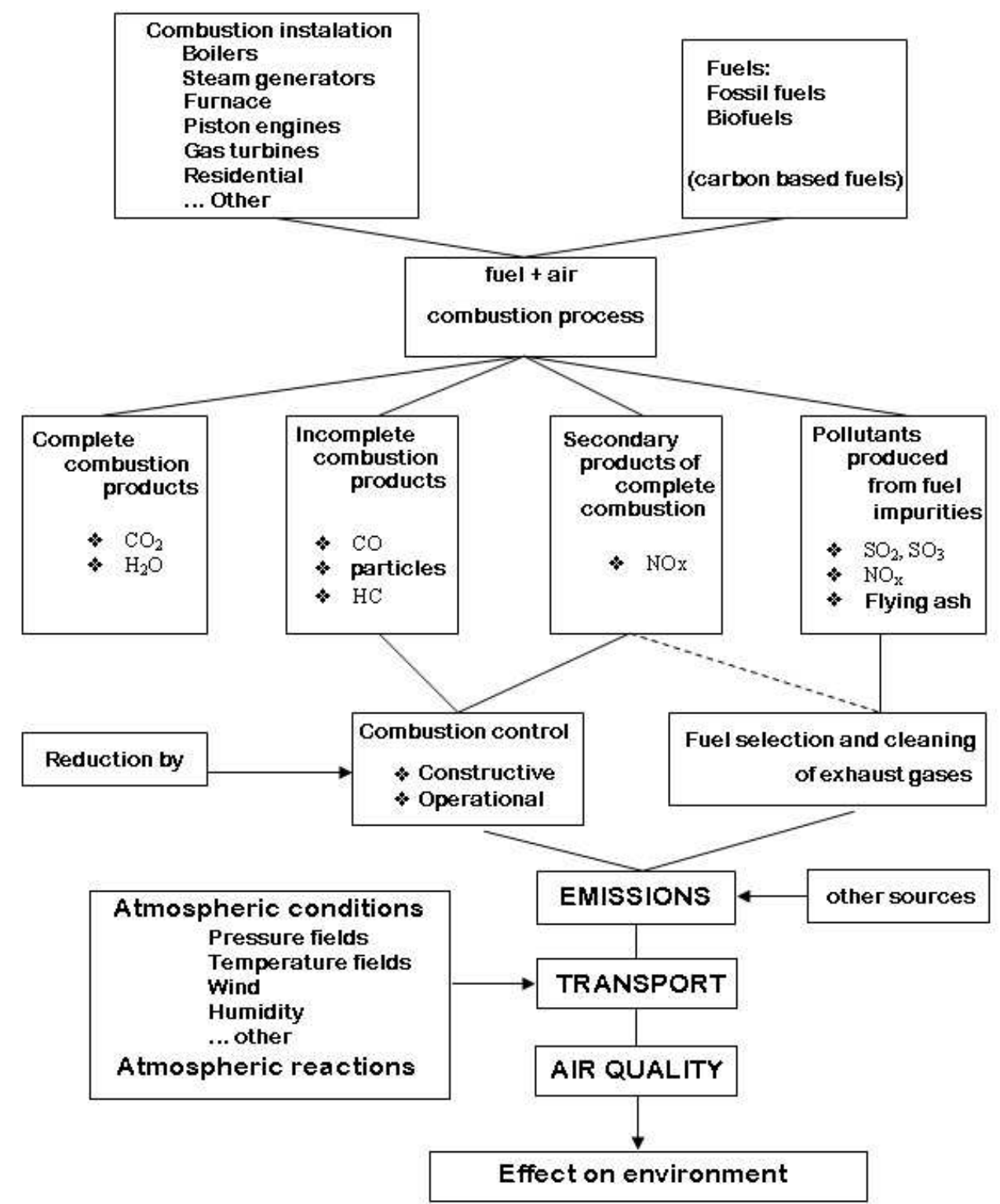

Fig. 1. Sources and products of anthropogenic pollution.

The fossil fuels, solid, liquid or gaseous, are mainly formed by carbon and hydrogen in various ratios. During the combustion of this fuels the carbon and hydrogen reacts with oxygen to form carbon dioxide and water. Due to incomplete combustion or other substances included in fuels, like nitrogen, sulphur, organic compounds, heavy metals and other compounds, besides $\mathrm{CO}_{2}$ and $\mathrm{H}_{2} \mathrm{O}$ other chemical compounds will be formed, 
compounds that are dangerous both to humans and environment if their concentrations in ambient air exceeds supportability limits. Equation 1 shows the products of complete combustions of an ideal fuel formed only from carbon and hydrogen.

$$
\mathrm{C}_{n} \mathrm{H}_{m}+\left(n+\frac{m}{4}\right) \mathrm{O}_{2} \rightarrow n \mathrm{CO}_{2}+\frac{m}{2} \mathrm{H}_{2} \mathrm{O}
$$

From an ecological point of view we can distinguish between several types of air pollutants, depending on how they affect the ecosystem (Ionel, 2006):

- pollutants that will have a direct impact on human health, like nitrogen oxides (NOx), carbon monoxide $(\mathrm{CO})$, sulphur oxides $\left(\mathrm{SO}_{2}\right)$ or volatile organic carbon (VOC);

- pollutants with direct impact on vegetation, like nitrogen oxides (NOx), sulphur oxides $\left(\mathrm{SO}_{2}\right)$ and chemical compounds of chlorine and hydrogen;

- pollutants that will form acids, like (NOx) and sulphur oxides $\left(\mathrm{SO}_{2}\right)$, especially when they are found in high concentrations and in same time into a humid atmosphere;

- $\quad$ persistent pollutants with a long life cycle and accumulated in soil and by the transfer thru biological plant-animal-human chain or accumulations in human body will have serious consequences on human health;

- pollutants with direct influence over climate, like carbon dioxide $\left(\mathrm{CO}_{2}\right)$ and methane $\left(\mathrm{CH}_{4}\right)$ with major impact on global warming issues.

There are many other atmospheric pollutants with anthropogenic origin but those listed above are of higher relevance for us and will be dealt in the next pages.

\section{Carbon monoxide (CO)}

Carbon monoxide is an odorless, colorless and toxic gas. Because it is impossible to see, taste or smell the toxic fumes, $\mathrm{CO}$ can kill you before you are aware it is in your home. At lower levels of exposure, $\mathrm{CO}$ causes mild effects that are often mistaken for the flu. These symptoms include headaches, dizziness, disorientation, nausea and fatigue. The effects of $\mathrm{CO}$ exposure can vary greatly from person to person depending on age, overall health and the concentration and length of exposure.

Carbon monoxide is mainly produced as an intermediary product of combustion processes in piston engines and boilers. The oxidation of $\mathrm{CO}$ into $\mathrm{CO}_{2}$ requires a temperature of minimum $990 \mathrm{~K}$ and a sufficient stationary time into the combustion chamber. If the combustion temperature is not high enough or uniform inside the combustion chamber, when the exhaust gases are evacuated some $\mathrm{CO}$ will not oxidize. The dependency between some pollutants and oxygen content of fuel mixture and excess air ration is given in figure 2 . Ambient $\mathrm{CO}$ concentrations in metropolitan areas are orders of magnitude higher than background. These levels are primarily associated with transportation emissions and are closely related to traffic density and meteorological conditions. Highest concentrations occur along major traffic arteries during morning and evening rush hours and decrease relatively rapidly with distance from roadways. Peak levels averaged over $1 \mathrm{~h}$ vary from about 5 to more than 10 ppmv in some cities. Elevated CO levels tend to plague cities that have high traffic densities and are located at relatively high altitudes. (Godish, 2004)

$\mathrm{CO}$ concentrations are significantly and more important than regulatory concerns would indicate. Carbon monoxide affects tropospheric concentrations of both hydroxyl radical $(\mathrm{OH}-)$ and $\mathrm{O} 3$ and, as a consequence, the oxidizing potential of the atmosphere. Because $\mathrm{CO}$ 
and $\mathrm{CH}_{4}$ (a major greenhouse gas) compete for $\mathrm{OH}-, \mathrm{CO}$ indirectly affects tropospheric concentrations of $\mathrm{CH}_{4}$ and stratospheric $\mathrm{H}_{2} \mathrm{O}$ vapor (derived from $\mathrm{CH}_{4}$ oxidation).

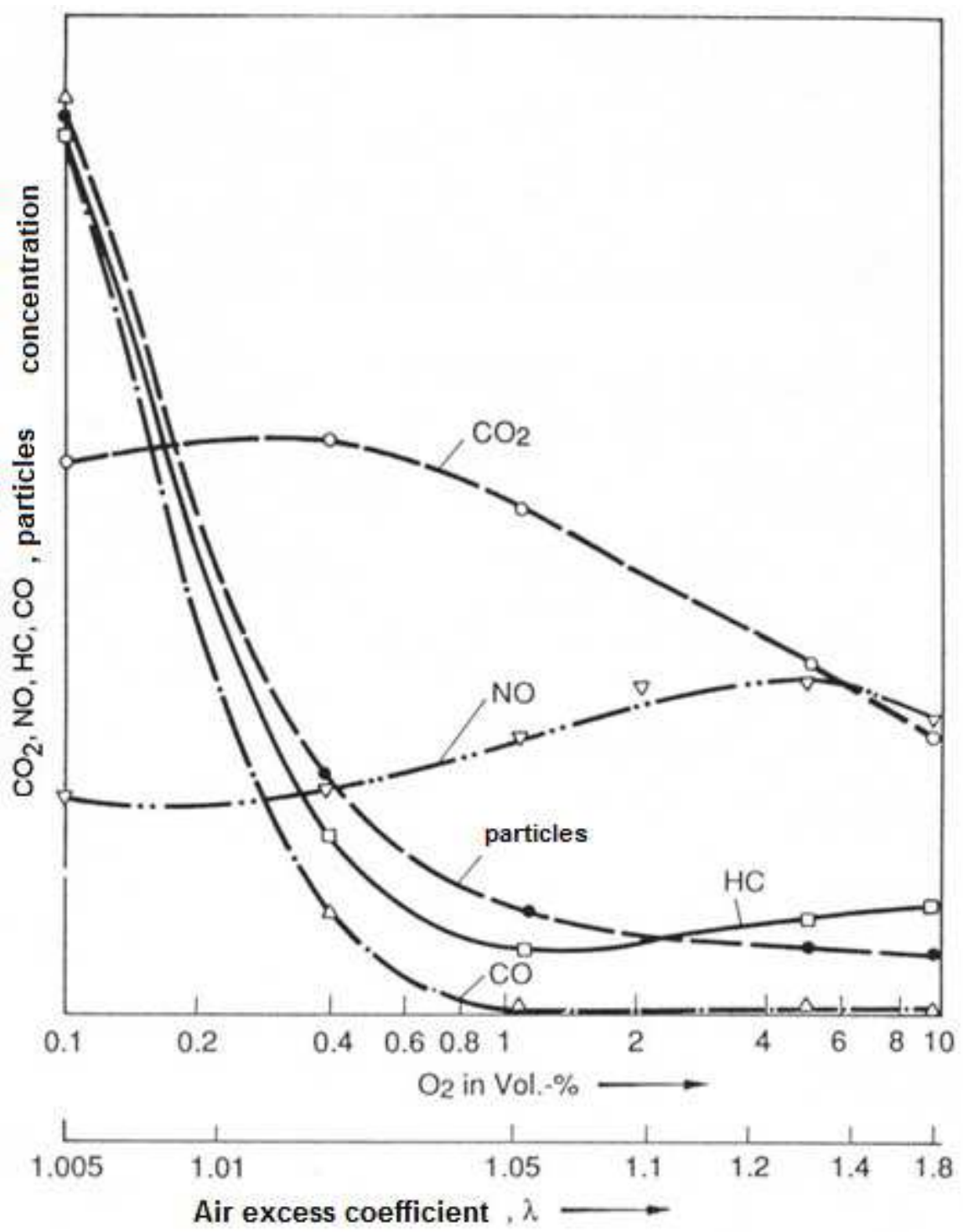

Fig. 2. Dependency of some pollutants to air-fuel ration value inside the combustion chamber

In figure 3 the contribution of key categories to EU-27 emissions of carbon monoxide are presented for year 2006 (EEA, 2008) and in figure 4 the sources of CO emissions, by sector, 
for USA in 2005 (US-EPA, 2005). A very important issue is that in the EU-27, emissions of CO decreased by just over $53 \%$ between 1990 and 2006. Decreased emissions were reported in all Member States except Romania. The largest absolute decreases were reported by France, Germany, Italy, Poland, Spain and the United Kingdom; however, these countries remained the largest emitters of CO in absolute terms in 2006. (EEA, 2008)

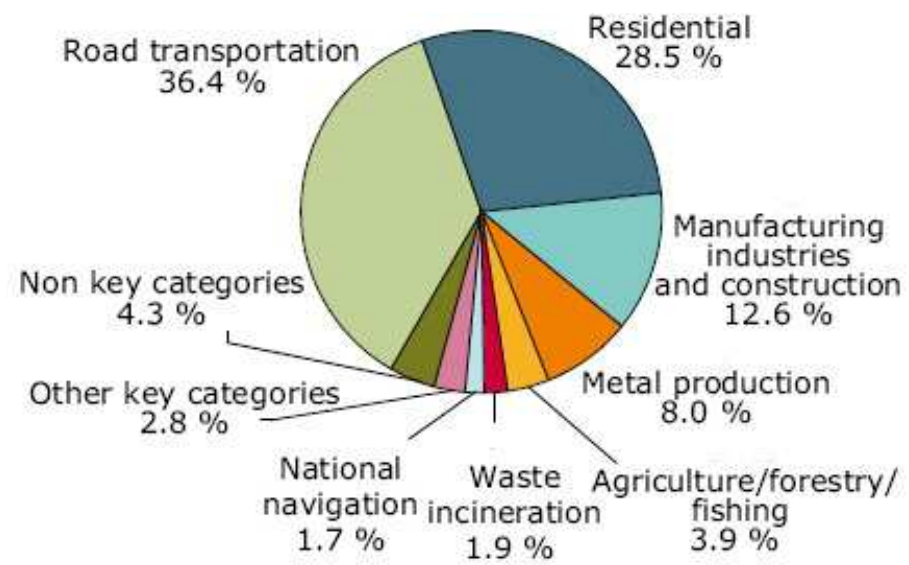

Fig. 3. EU-27 emission sources of carbon monoxide, 2006 (EEA, 2008).

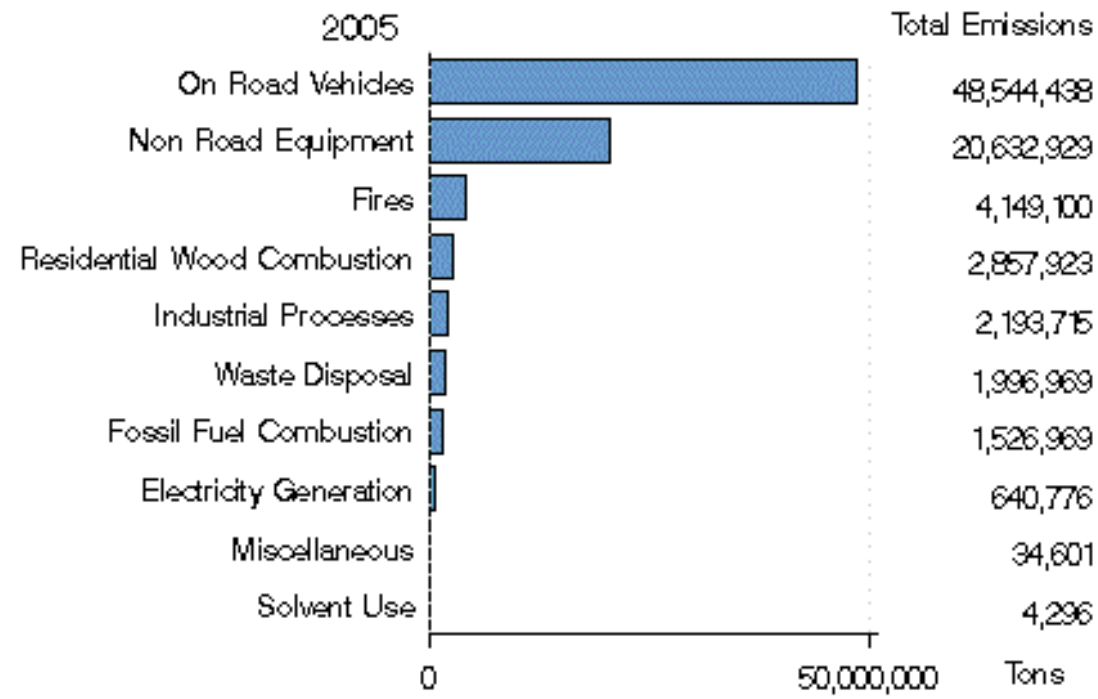

Fig. 4. USA emission sources of carbon monoxide, 2005 (US EPA, 2009).

Carbon monoxide is oxidized in the atmosphere to $\mathrm{CO}_{2}$ on reaction with $\mathrm{OH}$ - radicals:

$$
\mathrm{CO}+\mathrm{OH}^{-} \rightarrow \mathrm{CO}_{2}+\mathrm{H}^{-}
$$


Subsequent reactions of $\mathrm{H}$ - and oxygen $\mathrm{O}_{2}$ produce the highly reactive hydroperoxyl radical, $\mathrm{HO}_{2}$ :

$$
\mathrm{H}^{-}+\mathrm{O}_{2}+\mathrm{M} \rightarrow \mathrm{HO}_{2}^{-}+\mathrm{M}
$$

where $\mathrm{M}$ is an energy-absorbing molecule, e.g., nitrogen $\mathrm{N}_{2}$ or $\mathrm{O}_{2}$. From those to reactions we can conclude:

$$
\mathrm{CO}+\mathrm{H}^{-}+\mathrm{O}_{2} \rightarrow \mathrm{CO}_{2}+\mathrm{HO}_{2}^{-}
$$

In the presence of photons of light energy another reaction will occur:

$$
\mathrm{CO}+\mathrm{O}_{2}+h v \rightarrow \mathrm{CO}_{2}+\mathrm{O}_{3}
$$

where $\mathrm{O}_{2}$ is ground-state atomic oxygen and $h v$ is a photon of light energy.

As a result of these reactions, $\mathrm{CO}$ is converted to $\mathrm{CO}_{2}$, with one molecule of $\mathrm{O}_{3}$ produced for each $\mathrm{CO}$ molecule oxidized. As such, $\mathrm{CO}$ oxidation in the troposphere is an important (but low-level) source of $\mathrm{O}_{3}$.

The effects of carbon monoxide on human health are caused due to the fact that $\mathrm{CO}$ enters the bloodstream through the lungs and attaches to hemoglobin $(\mathrm{Hb})$, the body's oxygen carrier, forming carboxyhemoglobin $(\mathrm{COHb})$ and thereby reducing oxygen $\left(\mathrm{O}_{2}\right)$ delivery to the body's organs and tissues. High $\mathrm{COHb}$ concentrations are poisonous. Central nervous system (CNS) effects in individuals suffering acute $\mathrm{CO}$ poisoning cover a wide range, depending on severity of exposure: headache, dizziness, weakness, nausea, vomiting, disorientation, confusion, collapse, and coma. At lower concentrations, CNS effects include reduction in visual perception, manual dexterity, learning, driving performance, and attention level. Earlier work is frequently cited to justify the statement that $\mathrm{CO}$ exposure sufficient to produce $\mathrm{COHb}$ levels of ca. $5 \%$ would be sufficient to produce visual sensitivity reduction and various neurobehavioral performance deficits. In a recent literature reevaluation, however, the best estimate was that $(\mathrm{COHb})$ would have to rise to $15-20 \%$ before a $10 \%$ reduction in any behavioral or visual measurement could be observed. (Raub, 2002) Carbon monoxide ( $\mathrm{CO}$ ) may be the cause of more than one-half of the fatal poisonings reported in many countries: fatal cases also are grossly under-reported or misdiagnosed by medical professionals. Therefore, the precise number of individuals who have suffered from $\mathrm{CO}$ intoxication is not known.

In conclusion, $\mathrm{CO}$ poisoning occurs frequently; has severe consequences, including immediate death involves complications and often is overlooked. Efforts in prevention and in public and medical education should be encouraged. (Raub, 2002)

\section{Nitrogen oxides (NOx)}

Nitrous oxide concentrations in the atmosphere have been increasing steadily since preindustrial times, from $\sim 280$ to $\sim 320 \mathrm{ppbv}$ today. Estimated annual emissions to the atmosphere are $13.8 \mathrm{Tg}$ (tetragrams) $\mathrm{N} /$ year, with $\sim 70 \%$ being produced by nitrification and denitrification processes in undisturbed terrestrial environments and the world's oceans. About $3 \mathrm{Tg} \mathrm{N} /$ year, or $\sim 8 \%$, is associated with agricultural tillage, fertilizer use, and animal wastes. 
In case of combustion equipments the NOx are formed during the combustion process at high temperatures by the oxidation of nitrogen content of fuel and combustion air. In a first phase only $\mathrm{NO}$ is formed while the $\mathrm{NO}_{2}$ is mainly formed after the combustion in exhaust process when more $\mathrm{O}_{2}$ is present and into the atmosphere.

The main anthropogenic sources of nitrogen oxides are road transport and public electricity and heat sector. In figure 5 the contribution of key categories to EU-27 emissions of nitrogen oxides are presented for year 2006 (EEA, 2008) and in figure 6 the sources of NOx emissions, by sector, for USA in 2005 (US-EPA, 2005).

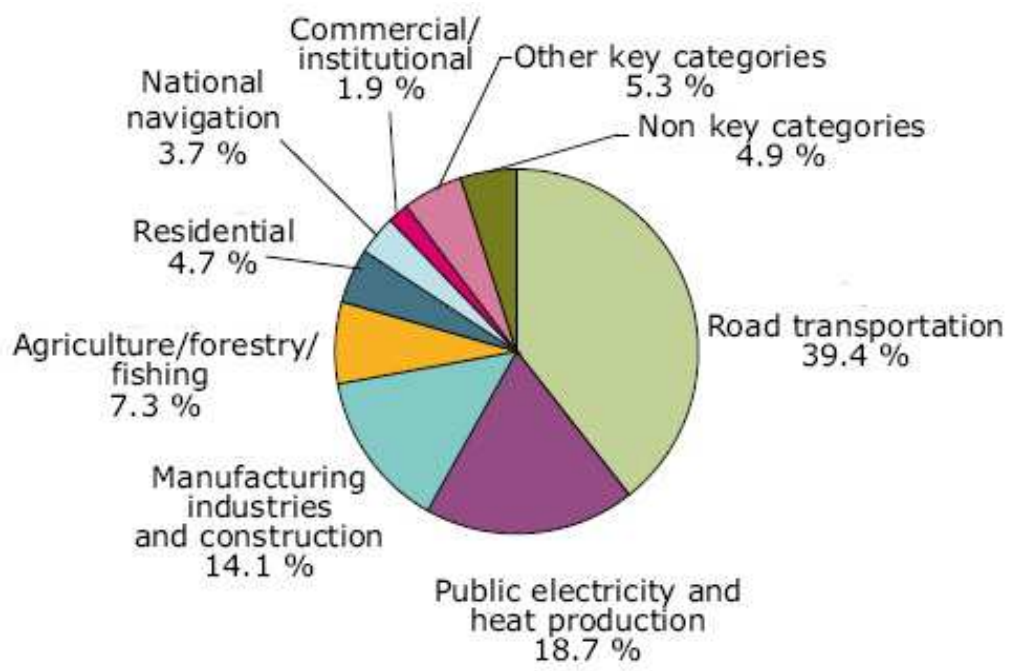

Fig. 5. EU-27 emission sources of nitrogen oxides, 2006 (EEA, 2008).

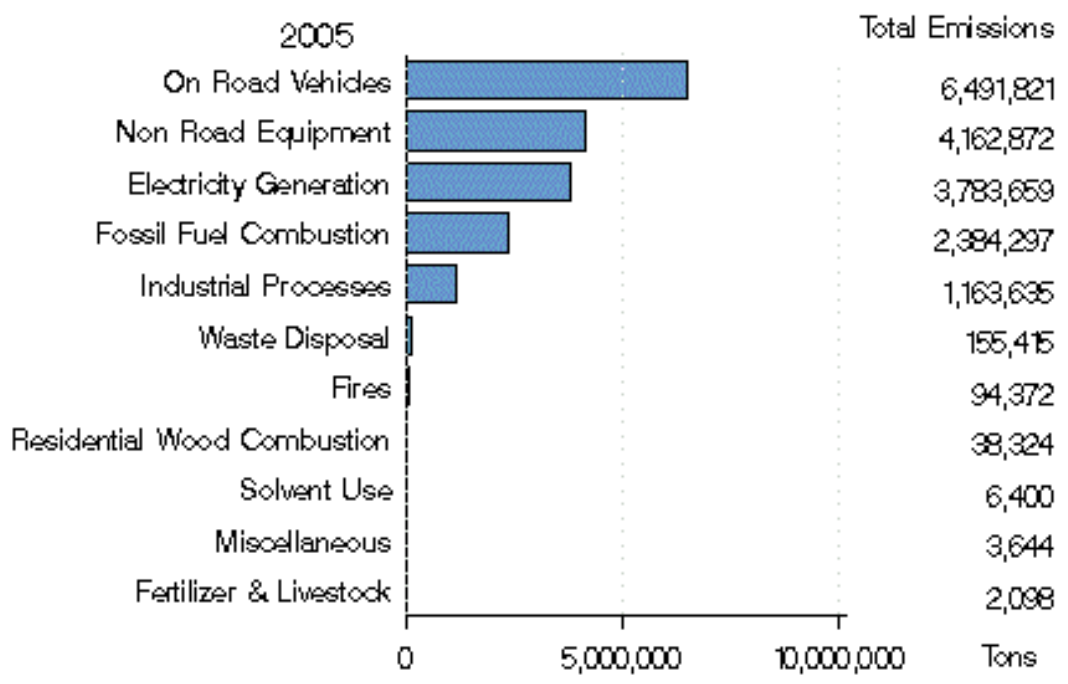

Fig. 6. USA emission sources of nitrogen oxides, 2005 (US EPA, 2009). 
Between 1990 and 2006, NOx emissions decreased in the EU-27 by $35 \%$. The change of total NOx emissions between 2005 and 2006 was rather small, a decrease of $1.8 \%$, mainly caused by reductions achieved in Germany, Italy and the United Kingdom. (EEA, 2008)

Increased atmospheric $\mathrm{N}_{2} \mathrm{O}$ levels pose two major environmental concerns: stratospheric $\mathrm{O}_{3}$ depletion and, because of its thermal absorptivity, global warming.

In case of combustions formed nitric oxides three mechanism are present: Thermal mechanism, the prompt mechanism and NOx formation from fuel nitrogen.

\subsection{Thermal mechanism of nitrogen oxide formation}

The thermal mechanism of nitric oxide formation during combustion was first studied by Zeldovici. The thermal mechanism occurs in combustion chamber in areas with higher oxygen concentration or in exhaust gases when nitrogen reacts with free oxygen atoms.

In areas when the combustion flame has high oxygen content the following reactions take place:

$$
\begin{aligned}
& \mathrm{O}+\mathrm{N}_{2} \rightarrow \mathrm{NO}+\mathrm{N} \\
& \mathrm{N}+\mathrm{O}_{2} \rightarrow \mathrm{NO}+\mathrm{O}
\end{aligned}
$$

In areas with rich fuel content and at temperatures over $1300{ }^{\circ} \mathrm{C}$ another reaction is more probable:

$$
\mathrm{N}+\mathrm{OH} \rightarrow \mathrm{NO}+\mathrm{H}
$$

The quantities of nitric oxides produced thru this mechanism are influenced by numerous factor but most relevant are:

- $\quad$ air-fuel excess ration factor $(\lambda)$;

- combustion temperature;

- $\quad$ air-fuel mixture residence time in combustion chamber areas with high temperatures.

Figure 7 gives an image on how temperature and residence time influences the NO formation during combustion process.

In the case of combustion in steam generators from large power plants, in installation where the ash is evacuated in dry state (particles) the contribution of thermal NOx mechanism to total NOx formation is up to $20 \%$. For installations where ash is evacuated in liquid state the thermal NOx contribution is up to $50 \%$.

In case of piston engines, gas turbines or in any other combustion process at high temperature rate the thermal NOx mechanism is responsible for $\sim 50 \%$ of total concentrations of NOx exhausted. In these cases a very important role plays the air-fuel ratio $(\lambda)$. As seen in figure 7 , if air-fuel ration is lower then 1 the formation of NO decreases.

\subsection{Prompt NO mechanism}

In areas where the combustion take place with low oxygen content nitric oxide can be formed by reactions between molecular nitrogen $\mathrm{N}_{2}$ and radicals like $\mathrm{CH}$ and $\mathrm{CN}$. This phenomenon was first discovered by Fenimore. It is widely accepted that reactions described bellow are responsible for NO formation by prompt NOx mechanism.

The majority of scientists agree that the prompt mechanism of NO formation can be neglected because the atomic nitrogen and $\mathrm{CN}$ radicals can only be formed in areas with very low air-fuel ratios. 


$$
\begin{gathered}
\mathrm{CH}+\mathrm{N}_{2} \rightarrow \mathrm{HCN}+\mathrm{N} \\
\mathrm{C}+\mathrm{N}_{2} \rightarrow \mathrm{CN}+\mathrm{N} \\
\mathrm{CN}+\mathrm{H}_{2} \rightarrow \mathrm{HCN}+\mathrm{H} \\
\mathrm{CN}+\mathrm{H}_{2} \mathrm{O} \rightarrow \mathrm{HCN}+\mathrm{OH} \\
\mathrm{HCN}(\mathrm{CN})+\mathrm{O} \rightarrow \mathrm{NO}+\mathrm{R}
\end{gathered}
$$

where $\mathrm{R}$ is an organic residue.

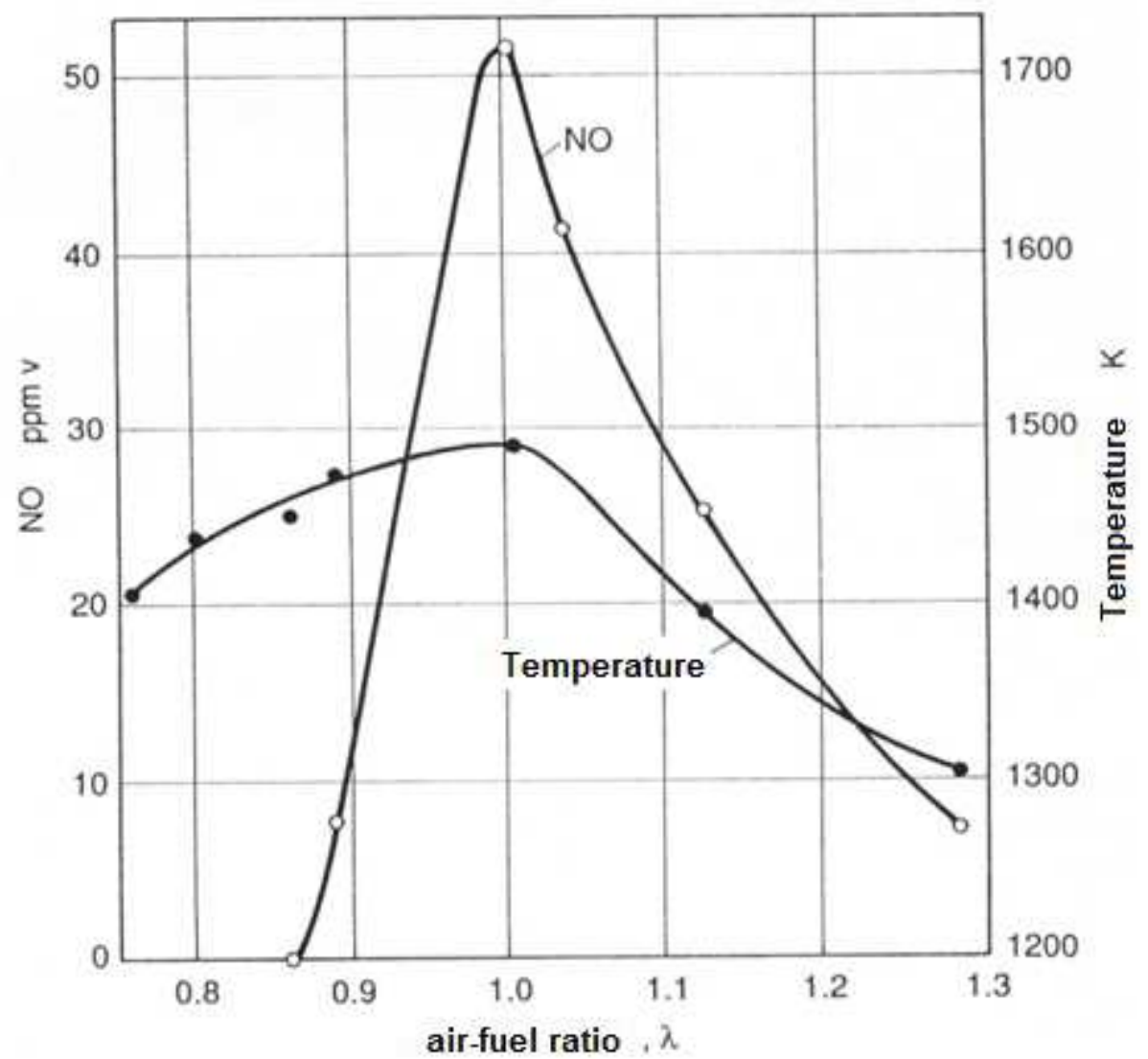

Fig. 7. Dependency between formed NO and combustion temperature and air-fuel ration $(\lambda)$

\subsection{Fuel NO mechanism}

The fuel NOx mechanism is also a flame based one but is more complex then prompt and thermal NOx mechanisms and partially unknown. However, it is known that first CN radicals are formed and their evolution in the presence of oxygen leads to NO formation. 
The decisive factors in fuel NOx mechanism are nitrogen content of fuel, oxygen concentration in combustion flame, reaction time and flame temperature.

The thermal NOx mechanism is much slower then prompt mechanism and the fuel NOx mechanism is faster then thermal NOx.

The sources of nitrogen fuel content are mainly the decay of proteins and nucleic acid from fossil material, mainly the aliphatic compounds as first, secondary and tertiary amines $\left(\mathrm{RNH}_{2}, \mathrm{R}_{1} \mathrm{R}_{2} \mathrm{NH}, \mathrm{R}_{1} \mathrm{R}_{2} \mathrm{R}_{3} \mathrm{~N}\right.$ ) or aromatic compound like pyridine $\left(\mathrm{C}_{5} \mathrm{H}_{5} \mathrm{~N}\right)$.

The complicated mechanism of fuel NOx formation can be synthesized as follows (Baumbach, 1992):

$$
\begin{aligned}
& \rightarrow \mathrm{NO} \\
\text { fuel } \mathrm{N} \rightarrow \mathrm{HCN} \rightarrow \mathrm{NCO} \rightarrow \mathrm{NH}_{i} & \rightarrow \mathrm{NO} \\
\mathrm{N} & \rightarrow \mathrm{N}_{2}
\end{aligned}
$$

Figure 8 gives an image of the NOx formation mechanisms to combustion temperature.

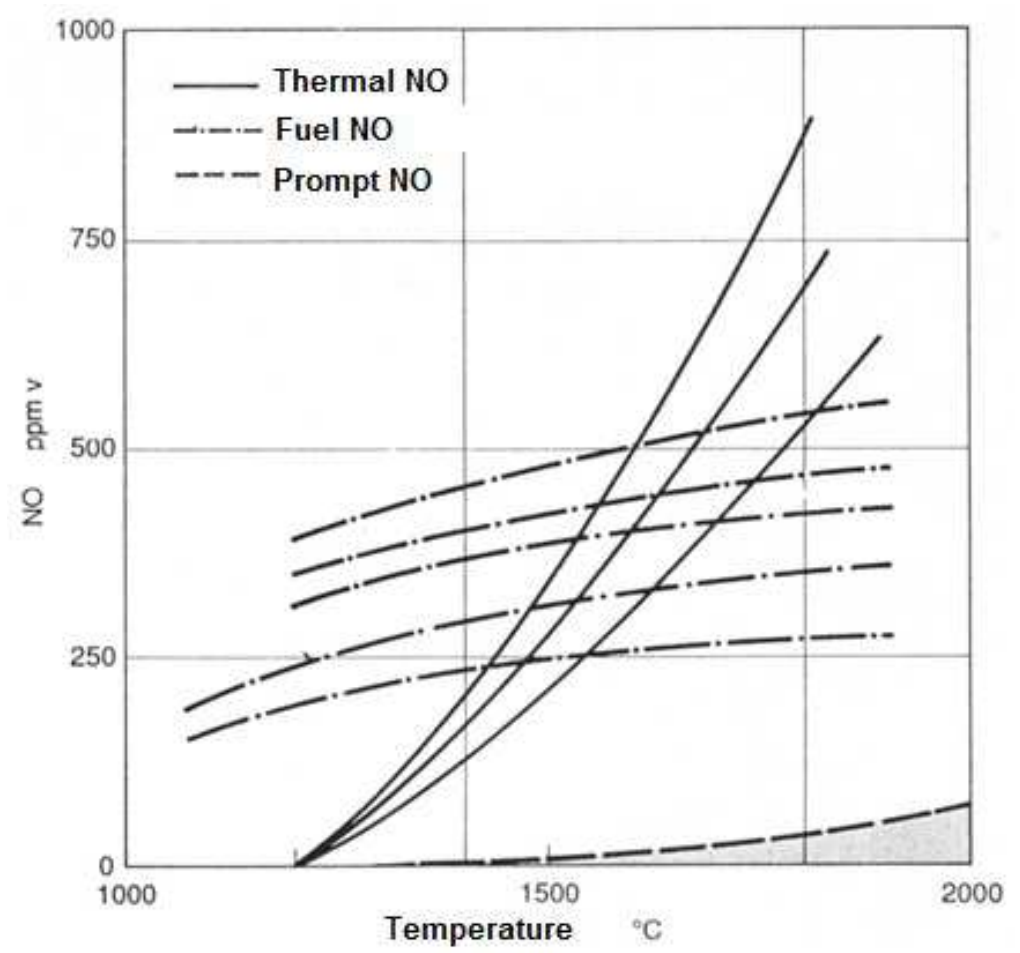

Fig. 8. Dependency between NO formation mechanisms and combustion temperature.

Into exhaust gases the nitric oxides consists only in nitrogen oxide (NO). The oxidation of $\mathrm{NO}$ to $\mathrm{NO}_{2}$ occurs partially in flue gases exhaust channels and in atmosphere, most important reactions are:

$$
2 \mathrm{NO}+\mathrm{O}_{2} \rightarrow 2 \mathrm{NO}_{2}
$$




$$
\mathrm{NO}+\mathrm{O}_{3} \rightarrow \mathrm{NO}_{2}+\mathrm{O}_{2}
$$

Another important reaction is the one that oxidize $\mathrm{NO}_{2}$ into nitric acid $\mathrm{HNO}_{3}$ in gaseous phase, because is a major contributor to acid rain by its diffusion in water droplets.

$$
\mathrm{NO}_{2}+\mathrm{OH}+\mathrm{M} \rightarrow \mathrm{HNO}_{3}+\mathrm{M}
$$

where $\mathrm{M}$ is a passive reaction partner.

\section{Sulphur oxides (SOx)}

All fossil fuels contain sulphur, most of which is released as sulphur dioxide during combustion. Almost all the anthropogenic sulphur contribution is due to fossil fuel combustion. Different fuels offer a wide range of sulphur contents (Colls, 2002):

- Oil and its by-products contain between $0.1 \%$ sulphur (paraffin) and 3\% (heavy fuel oil) in the form of sulphides and thiols. Petrol contains negligible sulphur in the context of overall mass emissions, although there can be an odor problem from conversion to hydrogen sulphide $\left(\mathrm{H}_{2} \mathrm{~S}\right)$ on catalytic converters.

- Coal contains $0.1-4 \%$ sulphur, mainly as flakes of iron pyrites $\left(\mathrm{FeS}_{2}\right)$. The average sulphur content of European coal reservoirs is 1.7\%.

- Natural gas (mainly methane, $\mathrm{CH}_{4}$ ) can be up to $40 \% \mathrm{H}_{2} \mathrm{~S}$ when it is extracted from the well. The sulphur is taken out very efficiently at a chemical processing plant before distribution, so natural gas is effectively sulphur free.

Global sulphur dioxide emissions are estimated to have increased from $4 \mathrm{Mt}$ (containing 2 Mt of sulphur) in 1860 to $150 \mathrm{Mt}$ in 1990. The emissions from the US and Europe increased steadily until the 1970s before coming under control. Sulphur emissions from the fastergrowing Asian region have continued to increase, due largely to coal combustion. Emissions from China are now comparable to those from the US, and in 1990 emissions from China, US and Russia accounted for over half the global total.

The EU-27 total SOx emissions in 2006 were $7946 \mathrm{Gg}$. This is almost a $70 \%$ reduction compared to the level of emissions reported in 1990. Since 1990, SOx emissions have increased in only two Member States: Romania (21.9 \%) and Greece (11.9 \%). Inspection of the time-series trends for some Member States shows some step changes in emission reductions have occurred since 1990. For example, emissions of $\mathrm{SO}_{2}$ in Slovenia fell considerably in 2001 and again in 2005 due to the introduction of flue gas desulphurization abatement equipment in thermal power plants.

In figure 9 the contribution of key categories to EU-27 emissions of sulphur oxides are presented for year 2006 (EEA, 2008) and in figure 10 the sources of SOx emissions, by sector, for USA in 2005 (US-EPA, 2005).

The natural sources are now heavily outweighed by human ones, principally fossil fuel combustion. Since $90 \%$ of the biogenic emission is as dimethyl sulphide, and an even higher proportion of the human emission is as $\mathrm{SO}_{2}$, we have a clear demarcation between the source types. Since most of the dimethyl sulphide comes from oceans in the southern hemisphere, and most of the human $\mathrm{SO}_{2}$ from fossil fuel emissions in the northern hemisphere, we also have a geographical split. 


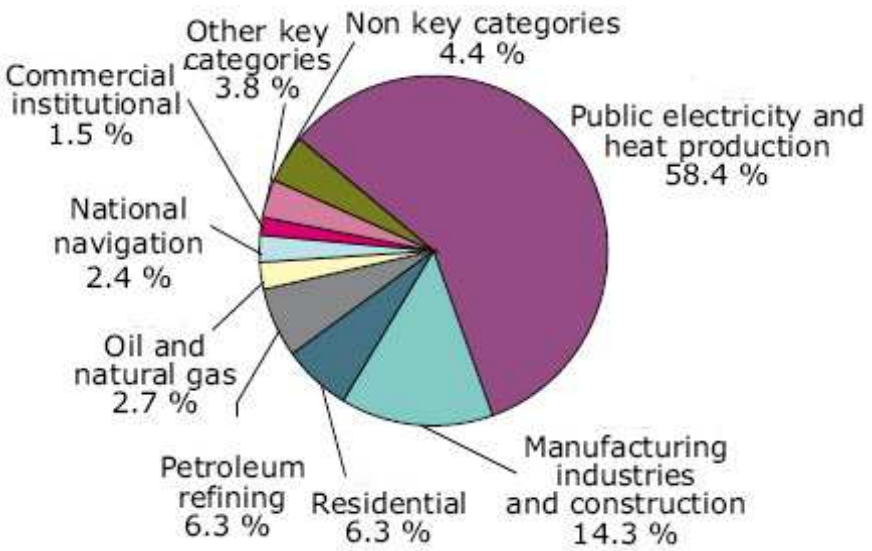

Fig. 9. EU-27 emission sources of sulphur oxides, 2006 (EEA, 2008).

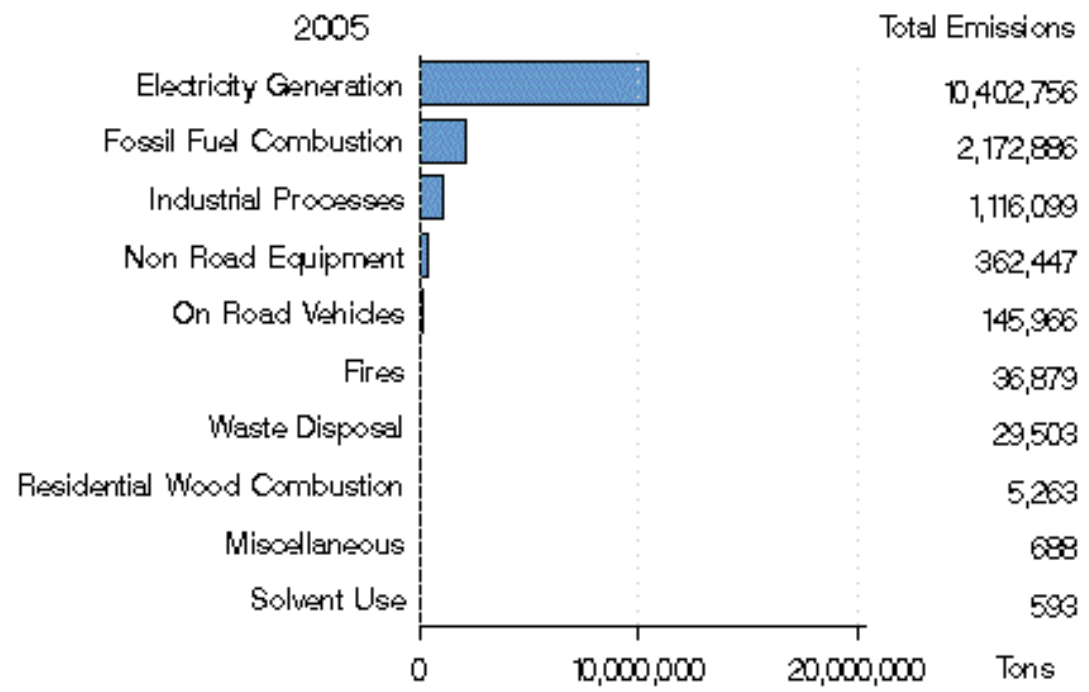

Fig. 10. USA emission sources of sulphur oxides, 2005 (US EPA, 2009).

Anthropogenic $\mathrm{SO}_{2}$ is almost exclusively formed during the combustion of fossil fuels with relevant sulphur content and most important is coal because the sulfur content of liquid and gaseous fossil fuels can be easily removed before combustion.

If the sulphur content of the fuel is totally combusted $\mathrm{SO}_{2}$ is formed thru the reaction:

$$
\mathrm{CH}_{3}-\mathrm{SH}+3 \mathrm{O}_{2} \rightarrow \mathrm{SO}_{2}+\mathrm{CO}_{2}+2 \mathrm{H}_{2} \mathrm{O}
$$

During the incomplete combustion with lack of oxygen elementary sulphur and hydrogen sulphide $\left(\mathrm{H}_{2} \mathrm{~S}\right)$ can form, at high temperatures. 


$$
\begin{gathered}
\mathrm{CH}_{3}-\mathrm{SH}+0.5 \mathrm{O}_{2} \rightarrow \mathrm{H}_{2} \mathrm{~S}+\mathrm{HCHO} \\
2 \mathrm{H}_{2} \mathrm{~S}+\mathrm{O}_{2} \rightarrow 2 \mathrm{H}_{2} \mathrm{O}+2 \mathrm{~S}
\end{gathered}
$$

Hydrogen sulphide $\left(\mathrm{H}_{2} \mathrm{~S}\right)$ can occur during the combustion process of low quality coals like lignite or into the piston engines exhaust gases after catalytic reduction if the engine works at high load and low air-fuel ratio.

During the combustion and in exhaust channels the $\mathrm{SO}_{2}$ can be oxidized to $\mathrm{SO}_{3}$ who will form with water content of flue gases sulphuric acid $\mathrm{H}_{2} \mathrm{SO}_{4}$. The $\mathrm{SO}_{2}$ conversion to $\mathrm{SO}_{3}$ is increased in the presence of vanadium of iron oxides at temperatures over $800{ }^{\circ} \mathrm{C}$.

Evacuated into the atmosphere $\mathrm{SO}_{2}$ reacts in proportion of $(1-2) \%$ /hour with oxygen, under the presence of ultraviolet radiation (uvr) and will form $\mathrm{SO}_{3}$.

$$
2 \mathrm{SO}_{2}+\mathrm{O}_{2}+u v r \rightarrow 2 \mathrm{SO}_{3}
$$

Afterwards, the $\mathrm{SO}_{3}$ will react with water vapors from the atmosphere to form sulphuric acid $\mathrm{H}_{2} \mathrm{SO}_{4}$. In periods of fog or days with high humidity the transformation rate of $\mathrm{SO}_{3}$ to $\mathrm{H}_{2} \mathrm{SO}_{4}$ can be up to $15 \%$.

$$
\mathrm{SO}_{3}+\mathrm{H}_{2} \mathrm{O} \rightarrow \mathrm{H}_{2} \mathrm{SO}_{4}
$$

Figure 11 is an illustrated view of some atmospheric reactions for $\mathrm{SO}_{2}$ and the historical evolutions of $\mathrm{SO}_{2}$ emissions into air.

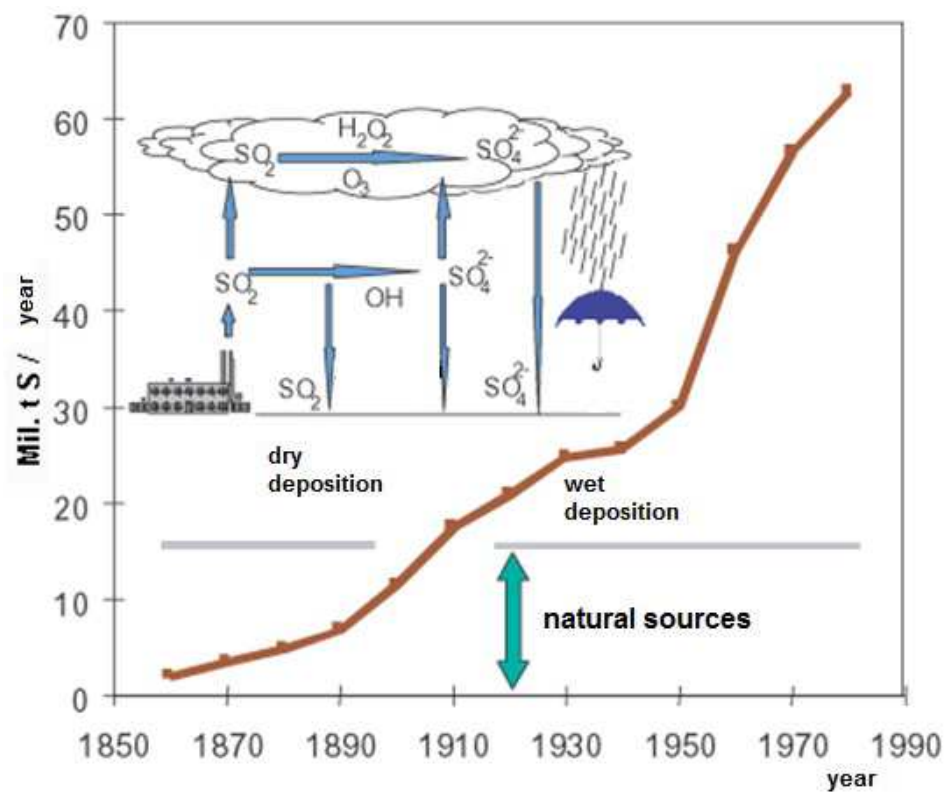

Fig. 11. $\mathrm{SO}_{2}$ atmospheric reaction and historical emissions. (Popescu, 2009) 


\section{Particulate matter}

Particulate matter is a collective term used to describe small solid and liquid particles that are present in the atmosphere over relatively brief (minutes) to extended periods of time (days to weeks). Individual particles vary in size, geometry, mass, concentration, chemical composition, and physical properties.

They may be produced naturally or as a direct or indirect result of human activities. Of major concern are particles $<10 \mu \mathrm{m}$ because they can remain suspended in the atmosphere where (depending on actual particle size) they can settle out relatively slowly. Atmospheric aerosol is characterized by these relatively small particles. The formation and increase of atmospheric aerosol by both natural and anthropogenic sources is a major air quality concern because aerosol particles may scatter light, reducing visibility, pose an inhalation hazard to humans and animals, affect climate on a regional and global scale.

Particulate matter can be described as being primary or secondary, based on its origin and processes of formation. Primary particles are emitted directly into the atmosphere from a variety of natural and anthropogenic sources. The natural particle sources include volcanoes, forest fires, ocean spray, biologic sources and the anthropogenic sources of particles are transportation, fuel combustion in stationary sources, a variety of industrial processes, solid waste disposal and miscellaneous sources such as agricultural activities and fugitive emissions from roadways. Secondary particles are formed in the atmosphere as a result of chemical processes involving gases, aerosol particles, and moisture.

In figure 12 the contribution of key categories to EU-27 emissions of particle matter, PM10 fraction, are presented for year 2006 (EEA, 2008) and in figure 13 the sources of particle matter, PM10 fraction, by sector, for USA in 2005 (US-EPA, 2005).

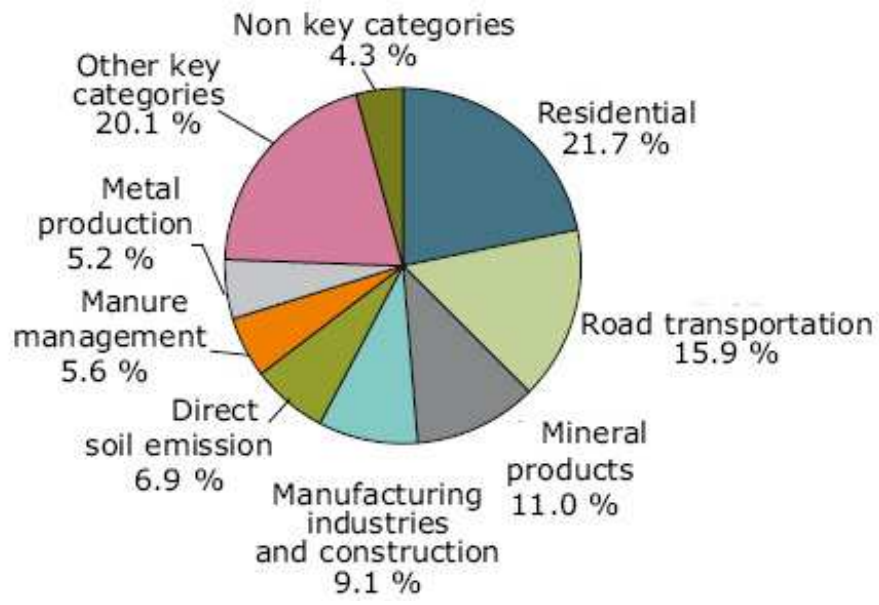

Fig. 12. EU-27 emission sources of PM10, 2006 (EEA, 2008). 


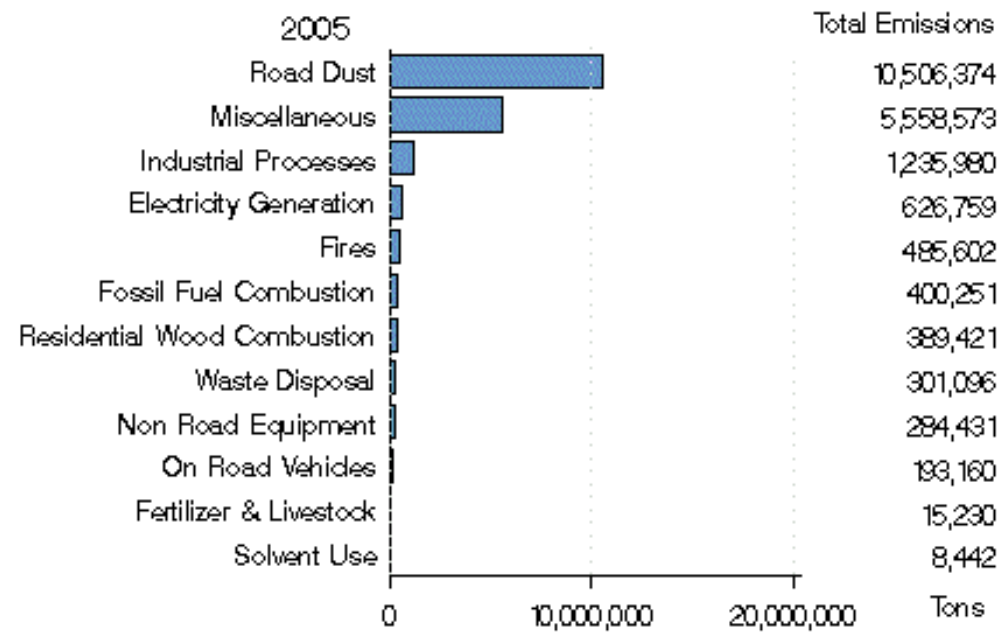

Fig. 13. USA emission sources of PM10, 2005 (US EPA, 2009).

In figure 14 the sources and diameter of representative particle matter fractions, thoracic (PM10), Respirable (PM4.0) and total suspended particles (TSP) are synthesized.

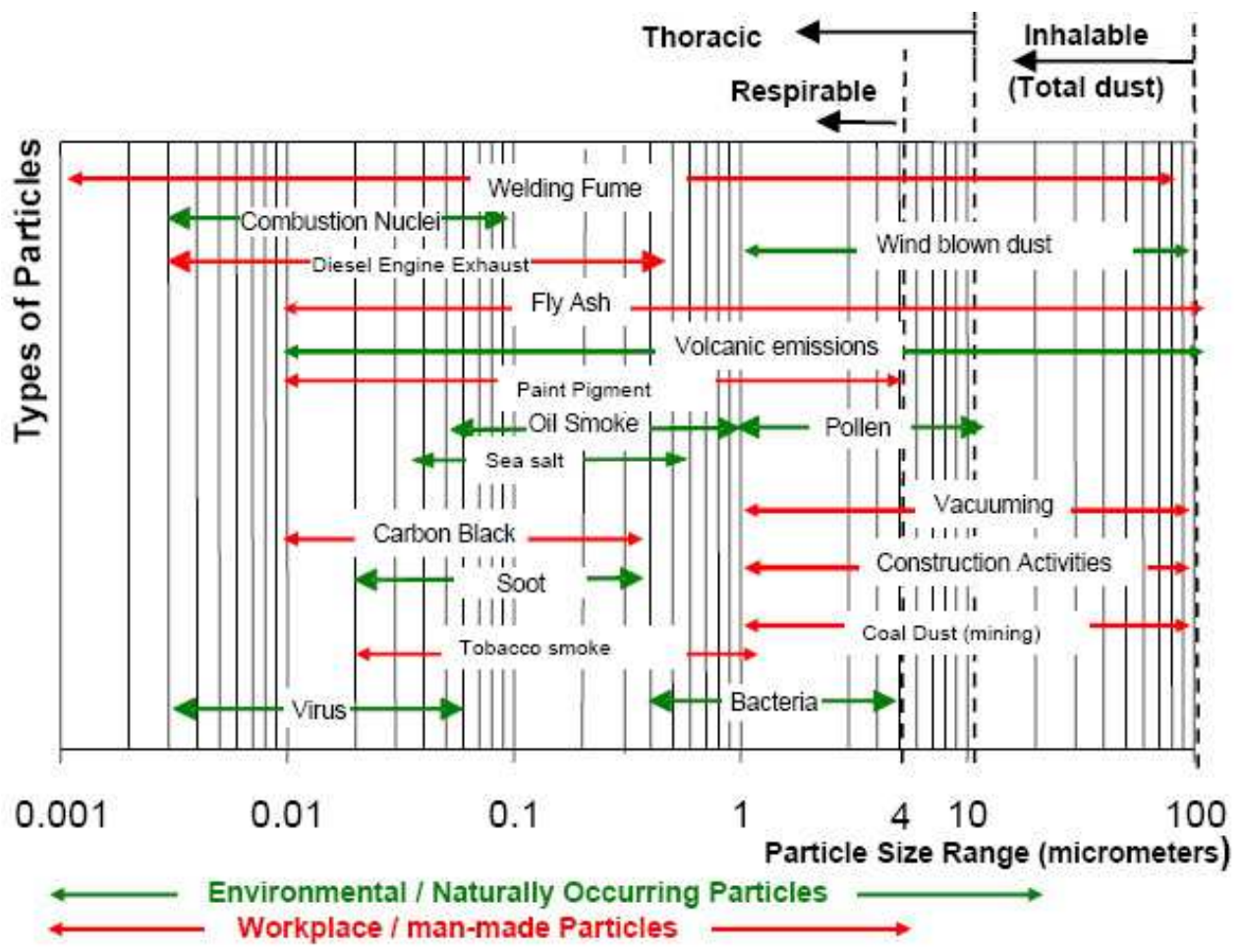

Fig. 14. Type of particles and their sources. (TSI, 2010) 
Into the combustion process particles are formed mainly from agglomerations of carbon and partially from hydrocarbons. The particle formation is encouraged by lack of oxygen at flame base and by high temperatures in this phase. The type of fuel is also relevant for particle formation.

During the fuel combustion the particles can form as soot, condensed hydrocarbons, ash or unburned carbon. For example, in the case of coal combustion, when the process starts first the volatile compounds is released while the mineral components are almost completely unburned. Large size particles (from 1 to $20 \mu \mathrm{m}$ ) are formed by mineral inclusions agglomeration on burned soot. During the soot fragmentation up to 5 large ash particles are formed, with a diameter from 10 to $20 \mu \mathrm{m}$ and a large number of particles with a diameter of 1 to $3 \mu \mathrm{m}$. Particles with a diameter lower then $0.1 \mu \mathrm{m}$ will form mainly due to vaporization and re-condensation of a part of the mineral components that are surrounding the ignited coal. In the combustion conditions of up to 1400 to $1600{ }^{\circ} \mathrm{C}$ appreciatively $1 \%$ of mineral components will vaporize in $\mathrm{Na}, \mathrm{As}, \mathrm{Fe}, \mathrm{SiO}$ and $\mathrm{Mg}$ vapors. This vapors will then diffuse (nucleation) into combustion chamber extremities where oxygen content is higher and will form a large number of very fine particle with a diameter of maximum $1 \mu \mathrm{m}$. All those particles will be then transported in atmosphere by exhaust gases. Figure 15 is a schematic representation of particle formation during fuel combustion.

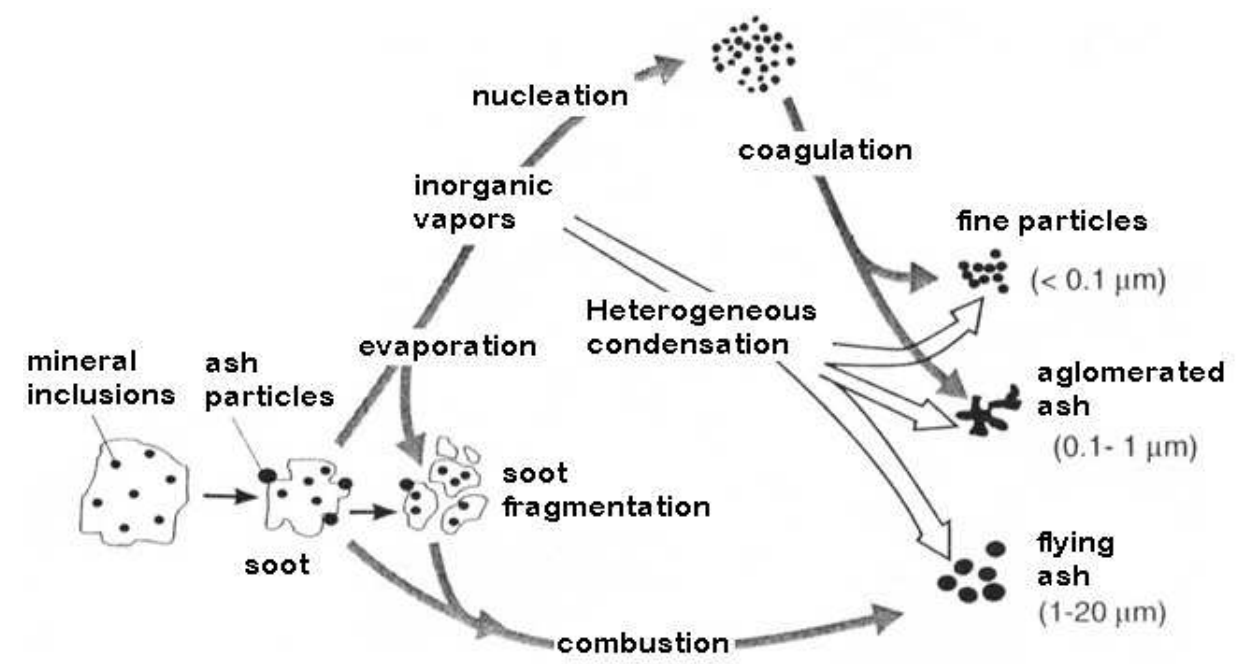

Fig. 15. Formation of particles in the combustion process of pulverized coal.

Before atmospheric particles can cause adverse health effects, they must enter and be deposited in the human respiratory system. Respiratory penetration and deposition depend on the aerodynamic size of particles, respiratory defense mechanisms, and breathing patterns. Particles can be described as inhalable, thoracic or respirable, based on their penetration and potential for deposition. Size ranges and fractional penetration are illustrated in figure 14. Particles with a diameter higher then $10 \mu \mathrm{m}$ generally do not pass through the nasal hairs and defense mechanisms of the upper respiratory system and are not of a public health concern. 


\section{Non Methane Volatile Organic Compounds}

The anthropogenic fraction of atmospheric VOCs is related to the unprecedented usage of fossil fuels for transport, the production of consumer goods and various industrial processes in the past centuries. The distinction between biogenic and anthropogenic VOCs in the atmosphere is far from straightforward because many VOC species are produced by both sources. Emissions of alkanes and alkenes, for example, are dominated by anthropogenic sources, but are also produced by soils, wetlands and oceans. (Koppmann, 2007)

The larges sources of NMVOC emissions are use of fossil fuel in transportation and chemistry industry. Mobile sources can be divided into emissions from the exhaust and fugitive emissions by evaporation. Stationary emissions from the use of fossil fuel are due to industrial applications (e.g. refineries and chemical sector). Emissions related to production, storage and delivery of fossil fuels predominately occur in those regions where extensive fossil fuel drilling activities exist. However, fugitive emissions can also occur from the transport and distribution of the fuel, such as ships, road tankers and fuel stations.

After their release into the atmosphere, VOCs are oxygenated by photochemical processes, which finally lead to their removal from the atmosphere. For most VOCs the process is initiated by atmospheric radicals like $\mathrm{OH}, \mathrm{O}_{3}, \mathrm{NO}_{3}$ and $\mathrm{Cl}$, with the $\mathrm{OH}$ radical being by far the most important reactant. The atmospheric lifetime of an individual VOC species is dependent on its chemical structure, the radical concentration and the intensity of solar radiation. When VOCs are degraded in polluted air masses, $\mathrm{NO}$ is oxygenated to $\mathrm{NO}_{2}$, which then gets photolysed and contributes to the formation of tropospheric ozone, a key issue in air pollution control.

In the EU-27, NMVOC emissions declined by just under $45 \%$ between 1990 and 2006 . Twenty-three countries reported reductions (Belgium, Germany, Luxembourg the Netherlands and the United Kingdom have reduced emissions by more than $60 \%$ during this period). The four countries that reported increased NMVOC emissions are Bulgaria, Greece, Poland and Romania.

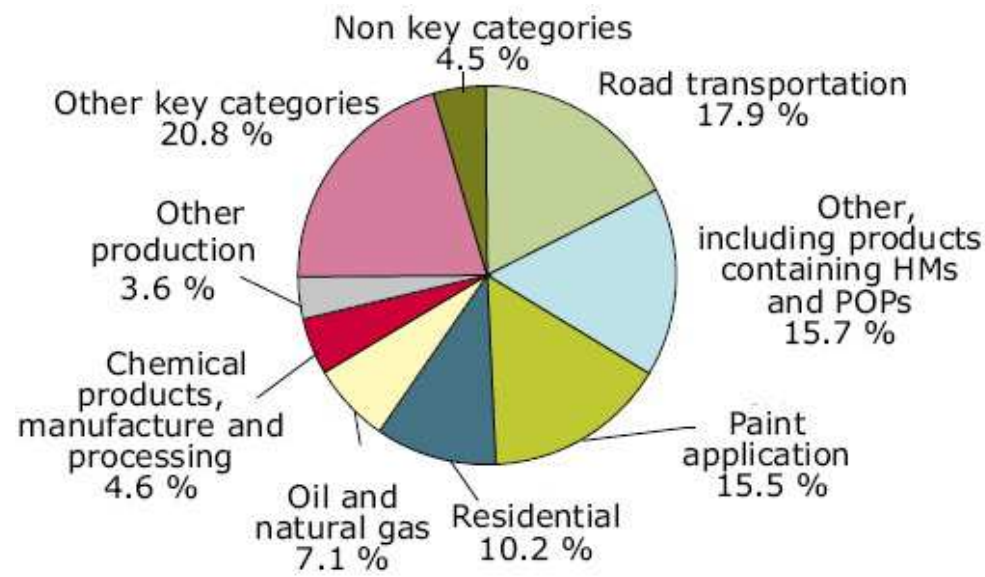

Fig. 16. EU-27 emission sources of NMVOC, 2006 (EEA, 2008). 


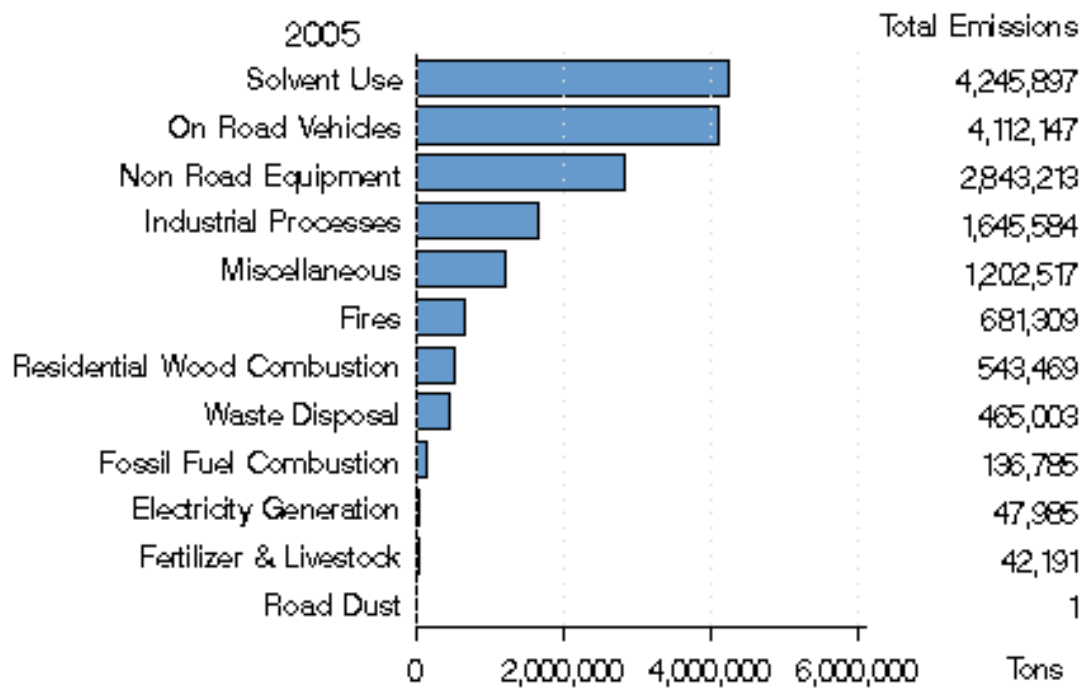

Fig. 17. USA emission sources of NMVOC, 2005 (US EPA, 2009).

The ability of NMVOCs to cause health effects varies greatly from those that are highly toxic, to those with no known health effect. As with other pollutants, the extent and nature of the health effect will depend on many factors including level of exposure and length of time exposed. Eye and respiratory tract irritation, headaches, dizziness, visual disorders, and memory impairment are among the immediate symptoms that some people have experienced soon after exposure to some organics. At present, not much is known about what health effects occur from the levels of organics usually found in homes. Many organic compounds are known to cause cancer in animals; some are suspected of causing, or are known to cause, cancer in humans.

\section{Relevant methods to control NOx and SOx emissions from fossil fuel combustion}

\subsection{NOx control}

Two primary categories of control techniques for NOx emissions are combustion control and flue gas treatment. Very often more than one control technique is used in combination to achieve desired NOx emission levels. A variety of combustion control techniques are used to reduce NOx emissions by taking advantage of the thermodynamic and kinetic processes. Some reduce the peak flame temperature; other reduces the oxygen concentration in the primary flame zone while other methods use the thermodynamic balance to reconvert NOx back to nitrogen and oxygen

In the low air-fuel excess ration firing techniques the principle is based on cutting back the amount of excess air, the lower oxygen concentration in the flame zone reduces NOx production. In some cases where too much excess air has become normal practice, thermal efficiency is improved. However, low excess air in the resulting flame may be longer and less stable, and carbon monoxide emissions may increase. Applying advanced optimization systems at four coal-fired power plants resulted in NOx emission reductions of 15 to $55 \%$. 
Another widely used method to control NOx emissions is the flue gas recirculation technology, when some of the flue gas, which is depleted in oxygen, is re-circulated to the combustion air. This has two effects: the oxygen concentration in the primary flame zone is decreased, and additional nitrogen absorbs heat, and reduces the peak flame temperature.

Injecting water or steam into the combustion chamber provides a heat sink that reduces peak flame temperature. (Schnelle \& Brown, 2002)

Low-NOx burners are designed to stage either the air or the fuel within the burner tip. The principle is similar to overfire air (staged air) or reburn (staged fuel) in a furnace. With staged-air burners, the primary flame is burned fuel rich and the low oxygen concentration minimizes NOx formation. Additional air is introduced outside of the primary flame where the temperature is lower, thereby keeping the thermodynamic equilibrium NOx concentration low, but hot enough to complete combustion. Staged-fuel burners introduce fuel in two locations. A portion of the fuel is mixed with all of the combustion air in the first zone, forming a hot primary flame with abundant excess air. NOx formation is high in this zone. Then additional fuel is introduced outside of the primary flame zone, forming a lowoxygen zone that is still hot enough for kinetics to bring the NOx concentration to equilibrium in a short period of time. In this zone, NOx formed in the primary flame zone reverts back to nitrogen and oxygen.

All those methods are primary methods to reduce NOx formation at the combustion chamber level. Also secondary methods for NOx reduction have been developed, like selective non-catalytic reduction (SNRC) and selective catalytic reduction (SCR).

Selective noncatalytic reduction uses ammonia $\left(\mathrm{NH}_{3}\right)$ or urea $\left(\mathrm{H}_{2} \mathrm{NCONH}_{2}\right)$ to reduce $\mathrm{NOx}$ to nitrogen and water. The overall reactions using ammonia as the reagent are:

$$
\begin{aligned}
2 \mathrm{H}_{2} \mathrm{~S}+\mathrm{O}_{2} & \rightarrow 2 \mathrm{H}_{2} \mathrm{O}+2 \mathrm{~S} \\
8 \mathrm{NH}_{3}+6 \mathrm{NO}_{2} & \rightarrow 7 \mathrm{~N}_{2}+12 \mathrm{H}_{2} \mathrm{O}
\end{aligned}
$$

The intermediate steps involve amine (NHi) and cyanuric nitrogen (HNCO) radicals.

The critical dependence of temperature requires excellent knowledge of the temperature profile within the furnace for placement of reagent injection nozzles.

In the case that the SNCR process is not controlled efficiently supplementary emissions will occur in exhaust gases, like $\mathrm{CO}, \mathrm{NH}_{3}$ or $\mathrm{N}_{2} \mathrm{O}$, called secondary emissions. In a typical application, SNCR produces about 30 to 50\% NOx reduction. Some facilities that require higher levels of NOx reduction take advantage of the low capital cost of the SNCR system, then follow the SNCR section with an SCR system. (Schnelle \& Brown, 2002)

In the SCR technology a catalyst bed can be used with ammonia as a reducing agent to promote the reduction reaction and to lower the effective temperature. An SCR system consists primarily of an ammonia injection grid and a reactor that contains the catalyst bed. A variety of catalyst types are used for SCR. Precious metals are used in the low temperature ranges. Vanadium pentoxide on titanium dioxide is a common catalyst for the medium temperature ranges and various aluminum silicates are used as high temperature catalysts.

While the SNCR technology can provide NOx reduction ratios of over $90 \%$ has a major disadvantage in economical cost and the necessity to retrofit the combustion facilities. 


\section{2. $\mathrm{SO}_{2}$ control}

$\mathrm{SO}_{2}$ control processes are used for coal-fired industrial boilers. $\mathrm{SO}_{2}$ and $\mathrm{HCl}$ controls are required for hazardous and municipal solid waste combustors. Many coal fired power plants use wet limestone scrubbers that have a relatively high capital cost in order to utilize inexpensive limestone reagent. Smaller, industrial-scale facilities typically use more expensive reagents in systems with lower equipment costs. Another solution to control $\mathrm{SO}_{2}$ emissions can be found in combustion of coals (anthracite) with high calorific value and low sulphur content.

The most relevant and used technology to reduce $\mathrm{SO}_{2}$ emissions from coal fired power plants is the combustion of coal with calcium based absorbers. Limestone is an inexpensive rock that is quarried and crushed. It can be used directly as a reagent either in aqueous slurry or by injection into a furnace where the heat decarbonates the limestone. This is a primary reduction process. The parameters that will influence the efficiency of $\mathrm{SO}_{2}$ removal are the type of combustor, the type of coal, the absorber quality and its time of residence into the facility.

The main reactions involved are:

$$
\begin{gathered}
\mathrm{CaCO}_{3} \stackrel{\sim 800 \mathrm{grd} . \mathrm{C}}{\rightarrow} \mathrm{CaO}+\mathrm{CO}_{2} \\
\mathrm{CaO}+\mathrm{SO}_{2} \rightarrow \mathrm{CaSO}_{3} \\
\mathrm{CaSo}_{3}+\frac{1 / 2 \mathrm{O}_{2}}{\rightarrow} \rightarrow \mathrm{CaSO}_{4}
\end{gathered}
$$

Other absorbers can also be used, like $\mathrm{CaOH}_{2}, \mathrm{Na}_{2} \mathrm{CO}_{3}$ or $\mathrm{NaOH}$ but they are more expensive than limestone.

The secondary methods for $\mathrm{SO}_{2}$ reduction can be classified as dry procedures, semidry and wet procedures.

A simplified process flow diagram for a coal fired power plant with wet limestone $\mathrm{SO}_{2}$ emission control system is presented in figure 18.

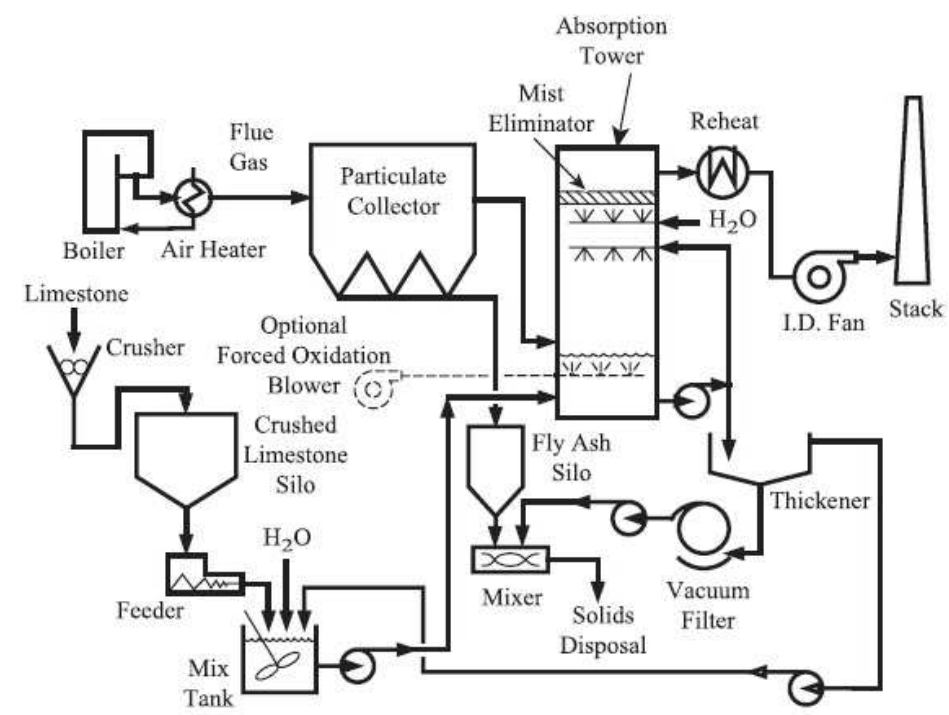

Fig. 18. Simplified wet limestone process flow diagram. (Schnelle \& Brown, 2002) 


\section{References}

Baumbach, G. (1992). Luftreihaltung - 2 auflange, Springer Verlag, Berlin, Germany Colls, J. (2002). Air Pollution - Second Edition, Spon Press, ISBN 0-20347602-6, UK

EEA, (2008). EEA technical report, no7/2008, Annual European Community LRTAP Convention emission inventory report 1990-2006, EEA office for official publication, Copenhagen

Godish, T. (1997). Air Quality, CRC Press LLC, ISBN 1-56670-231-3 Boca Raton

Godish, T. (2004). Air Quality - 4th Edition, CRC Press LLC, ISBN 0-203-49265-X, Boka Raton, Florida

Ionel, I. et al. (2010). Removal of mercury from municipal solid waste combustion gases, Journal of Environmental Protection and Ecology, 11 (1), 2010, ISSN 1311-5065

Ionel, I; Ungureanu C. \& Bisorca D. (2006). Thermo energy and environment, Politehnica Press, ISBN (10) 973-625-387-2, Timisoara, Romania

Koppmann, R. (2007). Volatile organic compounds in the atmosphere, Blackwell Publishing Ltd, ISBN 978-1-4051-3115-5, Singapore

Popescu, F. (2009). Alternative fuels. Biodiesel. Politehnica Press, ISBN 978-973-625-726-1, Timisoara, Romania

Popescu, F. et al. (2009). Ambient air quality measurements in Timisoara. Current situation and perspectives, Journal of Environmental Protection and Ecology, 10 (1), 2009, ISSN 1311-5065

Raub, J. A. (2002). Carbon Monoxide and the Nervous System. Neuroscience and Biobehavioral Reviews, 26(8), 2002, ISSN 925-940

Raub, J. A. et al. (2000). Carbon Monoxide Poisoning - a Public Health Perspective. Toxicology (145):1-14, 2000

Schnelle, K.B \& Brown, C.A. (2002). Air pollution control technology handbook, CRC Press, ISBN 0-8493-9588-7, Boca Raton. Florida

TSI. (2010). Type of particles. Technical document, TSI Incorporated, www.tsi.com

US EPA (2009). United States Environmental Protection Agency, Air Emission Sources, November 04, 2009, http:/ /www.epa.gov/air/emissions/index.htm, 2009 


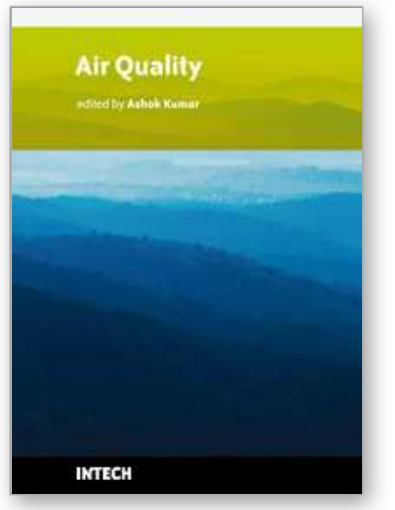

\author{
Air Quality \\ Edited by Ashok Kumar
}

ISBN 978-953-307-131-2

Hard cover, 382 pages

Publisher Sciyo

Published online 18, August, 2010

Published in print edition August, 2010

Air pollution is about five decades or so old field and continues to be a global concern. Therefore, the governments around the world are involved in managing air quality in their countries for the welfare of their citizens. The management of air pollution involves understanding air pollution sources, monitoring of contaminants, modeling air quality, performing laboratory experiments, the use of satellite images for quantifying air quality levels, indoor air pollution, and elimination of contaminants through control. Research activities are being performed on every aspect of air pollution throughout the world, in order to respond to public concerns. The book is grouped in five different sections. Some topics are more detailed than others. The readers should be aware that multi-authored books have difficulty maintaining consistency. A reader will find, however, that each chapter is intellectually stimulating. Our goal was to provide current information and present a reasonable analysis of air quality data compiled by knowledgeable professionals in the field of air pollution.

\title{
How to reference
}

In order to correctly reference this scholarly work, feel free to copy and paste the following:

Francisc Popescu and loana Ionel (2010). Anthropogenic Air Pollution Sources, Air Quality, Ashok Kumar (Ed.), ISBN: 978-953-307-131-2, InTech, Available from: http://www.intechopen.com/books/airquality/anthropogenic-air-pollution-sources

\section{INTECH}

open science | open minds

\section{InTech Europe}

University Campus STeP Ri

Slavka Krautzeka 83/A

51000 Rijeka, Croatia

Phone: +385 (51) 770447

Fax: +385 (51) 686166

www.intechopen.com

\section{InTech China}

Unit 405, Office Block, Hotel Equatorial Shanghai No.65, Yan An Road (West), Shanghai, 200040, China 中国上海市延安西路65号上海国际贵都大饭店办公楼405单元 Phone: +86-21-62489820

Fax: $+86-21-62489821$ 
(C) 2010 The Author(s). Licensee IntechOpen. This chapter is distributed under the terms of the Creative Commons Attribution-NonCommercialShareAlike-3.0 License, which permits use, distribution and reproduction for non-commercial purposes, provided the original is properly cited and derivative works building on this content are distributed under the same license. 